\title{
Operator of Medical Device ICSR Terminology
}

National Cancer Institute

\section{Source}

National Cancer Institute. Operator of Medical Device ICSR Terminology. NCI Thesaurus. Code C54584.

Terminology used in Individual Case Safety Reports to specify information on an operator of a medical device, section D5 of FDA MedWatch Form. 